\title{
Change in the Annual Water Withdrawal-to-Availability Ratio and Its Major Causes: An Evaluation for Asian River Basins Under Socioeconomic Development and Climate Change Scenarios
}

\author{
Ayami Hayashi ${ }^{1}$, Keigo Akimoto ${ }^{1,2}$, Takashi Homma ${ }^{1}$, Kenichi Wada ${ }^{1} \&$ Toshimasa Tomoda $^{1}$ \\ ${ }^{1}$ Systems Analysis Group, Research Institute of Innovative Technology for the Earth, Kyoto, Japan \\ ${ }^{2}$ Graduate School of Art and Science, The University of Tokyo, Tokyo, Japan \\ Correspondence: Ayami Hayashi, Systems Analysis Group, Research Institute of Innovative Technology for the \\ Earth (RITE), 9-2 Kizugawadai, Kizugawa-shi, Kyoto 619-0292, Japan. Tel: 81-77-475-2304. E-mail: \\ ayami@rite.or.jp
}

Received: October 30, 2013 Accepted: March 4, 2014 Online Published: April 29, 2014

doi:10.5539/eer.v4n2p34

URL: http://dx.doi.org/10.5539/eer.v4n2p34

\begin{abstract}
More than half of the world's population lives in Asia, and ensuring a stable water supply is a critical issue. This study evaluates changes in the annual water withdrawal-to-availability ratio (WAR), and the major causes thereof, for each of Asian river basins under different socioeconomic development and climate change scenarios. According to our evaluation, the WAR will increase in $59 \%-61 \%$ of the Asian river basin areas by around 2030 , as a result of population growth and the increase in per capita municipal and industrial water withdrawals. On the other hand, the WAR will decrease in $8 \%-16 \%$ of such areas, due to the increase in water availability associated with global warming and a decrease in per capita water agricultural withdrawal. After 2030, there will be a reduction of areas with increasing WAR because of a slowdown in the growth of both population and per capita municipal and industrial water withdrawals, while there will be an expansion of areas with decreasing WAR caused by continual decrease in per capita agricultural water withdrawal and intensified water availability. Significant measures to suppress WAR increase will differ by river basin, depending on the causes for the WAR increase. For instance, measures to deal with population increase and efforts to improve industrial and municipal water use by around 2030 will be important in the Huang He river basin. In the Indus river basin, coping with the decrease in water availability after around 2030 will be important. In addition, measures to handle population increase will be necessary.
\end{abstract}

Keywords: water resource management, water withdrawal-to-availability ratio, socioeconomic development, climate change

\section{Introduction}

More than half of the world's population lives in Asia, and the Asian population is projected to reach around 4.5 billion in the middle of this century (United Nations [UN], 2011). Furthermore, the number of people living in river basins threatened by severe water stress is estimated to increase, although the absolute value varies depending on assumptions on the criterion for severe water stress, scenarios on socioeconomic development and climate change and so on. For instance, according to an evaluation by Arnell (2004) based on a criterion, per capita annual water availability (PWA) $<1000 \mathrm{~m}^{3}$, about 1 billion people in South Asia and East Asia were threatened by severe water stress in 1995 . The 'water availability' includes renewable surface and subsurface runoff, and is also called as 'blue water resource'. Hayashi et al. (2013) estimated figures for the population under severe water stress based on the following criterion: $0.4 \leq$ a ratio of the annual water withdrawal to water availability (WAR) (Raskin et al., 1997), in which the annual water withdrawal is represented by the sum of annual water withdrawals of municipal, industrial, and agricultural sectors, and reported that the figure in Asia would increase from 1.4 billion in 2000 to 2.4 billion in 2050 and 2.1 billion in 2100 . An evaluation based on the following criterion: cumulative withdrawal-to-demand ratio $(\mathrm{CWD}) \leq 0.5$ (Hanasaki et al., 2013) stated that the population in Asia under severe water stress would increase from 1.7 billion in 2000 to 2.0-3.2 billion by the middle of this century, and 1.6 to 3.1 billion by the end of this century. (The ranges mainly resulted from differences in assumptions related to population growth). These results suggest that a stable fresh water supply 
become a critical issue in Asia. Meanwhile, from the viewpoint of water resource management, important points include not only whether the indexes will exceed their criteria for 'severe water stress', but also whether they will become increasingly or decreasingly severe. If they change, an assessment of the causes would be meaningful.

Gosling and Arnell (2013) and Gerten at al. (2013) evaluated the impacts of climate change on the PWA and WAR, maintaining socioeconomic development scenario unchanged; and they stated that the severity of water stress will increase around the Mediterranean, in parts of Europe, North and South America, and southern Africa, while it will decrease in regions such as East Asia. Hanasaki et al. (2013) presented the CWD change for different scenarios on socioeconomic development and climate change. They stated that water stress conditions will be influenced by both of climate change and water use change, although the contributions by climate change and water use change will vary among regions and scenarios. Fung et al. (2011) evaluated the PWA for 112 large river basins throughout the world for two global mean temperature change scenarios, and stated that, assuming the 2060s population scenario (UN, 2007), the water stress condition would worsen in $71 \%$ and $74 \%$ of the river basins at scenarios of $+2{ }^{\circ} \mathrm{C}$ and $+4{ }^{\circ} \mathrm{C}$ (relative to the pre-industrial level), respectively. They described that the direction of change in the water stress condition was highly dependent on the population assumption for most of the basins, although climate change dominated the direction for a small number of basins. Alcamo et al. (2007) evaluated the WAR in the 2050s for the A2 and B2 scenarios of the Special Report on Emissions Scenarios (SRES) (Intergovernmental Panel on Climate Change [IPCC], 2000). They reported that the WAR would increase (i.e., the water stress condition would worsen) in over $62 \%-76 \%$ of the world river basin areas, and would decrease (i.e., the water stress condition would improve) in over $20 \%-29 \%$ of the world basin areas. The principal cause of the decreasing WAR is greater water availability due to climate change, while the principal cause of the increasing WAR is growing water withdrawals. Furthermore, for areas with increasing water withdrawals, they made estimations regarding the contributions of different sectors to increases in water withdrawals. They stated that the municipal sector would make the greatest contribution, since this sector represents the largest increases in $80 \%-86 \%$ of the aforementioned areas. These studies are interesting for understanding directions of change in water stress condition and the principal cause of the change. However, a limitation of these studies is a lack of quantitative comparisons of the impacts on the water stress change among major causes. For instance, the study by Alcamo et al. (2007) remains unclear whether the increase in the municipal water withdrawal or the decrease in water availability has the greatest impact on the WAR increase. In the study by Fung et al. (2011), the assumptions for water demand based on population figures are too simple to take into account impacts caused by changes in human activity.

To clarify the impacts on the water stress condition due to each of major causes, we decompose a change rate of the water stress index into the sum of change rates of major factors, and evaluate these change rates for different scenarios on socioeconomic development and climate change during this century. We adopted the WAR as a water stress index to take into account the human activity change in municipal, industrial, and agricultural sectors. A grid-based water supply-demand model is utilized to evaluate the WAR by river basin keeping a consistency with socioeconomic development and climate change scenarios. The evaluation is conducted focusing on Asian river basins, since a stable fresh water supply will probably become a critical issue in Asia as mentioned above, and information on the causes of the water stress change will be important for the water resource management. This paper describes the evaluations throughout Asian river basins. For some river basins that are currently threatened by high water stress, the details of the causes for the water stress change are described together with preliminary consideration for possible measures to alleviate the water stress.

\section{Methodology}

\subsection{The Annual Water Withdrawal-to-Availability Ratio}

The numerator of this ratio, the annual water withdrawals, are represented by the sum of annual water withdrawals of municipal, industrial, and agricultural sectors, and the denominator, the water availability, is represented by annual runoff (renewable freshwater). According to Raskin et al. (1997), the areas with WAR < 0.2 had low or no stress; areas with $0.2 \leq$ WAR $<0.4$ had medium stress; and areas with $0.4 \leq$ WAR had high (severe) stress. This ratio is simple to apply to global-scale and long-term evaluations, and has been utilized in many studies (Vörösmarty et al., 2000; Oki \& Kanae, 2006; Alcamo et al., 2007).

It also has the following disadvantages: 1) A gap between the subannual distribution of water availability and water demand is possibly overlooked; and 2) overestimation is possible if not only primary water withdrawal but also secondary water withdrawal (i.e., wastewater use) is counted. Hanasaki et al. (2008) proposed a sophisticated index, CWD, to cope with these disadvantages, in which daily water withdrawal from a river and 
daily potential water consumption demand is simulated by grid with a spatial resolution of one degree. According to their comparison between the WAR and the CWD, the WAR tends to underestimate the water stress in grids such as the Sahel, the Asian monsoon region, and southern Africa, and it has extremely large value (e.g., 100) in some grids. However, their results simultaneously show that there is a strong correlation between the WAR and the CWD for almost all grids. With an understanding of this situation, we adopted the WAR, which would not cause a serious problem in this study.

\subsection{Change Rates of the WAR and Major Associated Factors}

The WAR is denoted as Equation (1).

$$
W A R=\frac{P \cdot D}{R}
$$

Where $P, D$, and $R$ are population, per capita annual water withdrawal, and annual water availability, respectively; and $D$ is expressed by the sum of $M$ (per capita annual municipal water withdrawal), $I$ (per capita annual industrial water withdrawal), and $A$ (per capita annual municipal water withdrawal).

Therefore, the change rate of WAR during a period from $t_{1}$ to $t_{2}$ is denoted as Equation (2).

$$
\Delta W A R=\Delta P+\Delta D-\Delta R
$$

Where $\triangle W A R, \Delta P, \Delta D$, and $\Delta R$ are the change rates for $W A R, P, D$, and $R$, respectively; and the formula $(\Delta X)$ denoted by Equation (3) is applied to $\triangle W A R, \Delta P, \Delta D$, and $\Delta R$.

$$
\Delta X=\frac{1}{t_{2}-t_{1}} \cdot \ln \left(\frac{X_{2}}{X 1}\right)
$$

Furthermore, we introduce the approximate expression of $\Delta D$, as denoted by Equation (4), to understand the separate contributions of municipal, industrial, and agricultural water withdrawals on the per capita annual water withdrawal.

$$
\Delta D \approx \Delta^{\prime} M+\Delta^{\prime} I+\Delta^{\prime} A
$$

Where the formulae applied to $\Delta^{\prime} M, \Delta^{\prime} I$, and $\Delta^{\prime} A$ are:

$\frac{1}{t_{2}-t_{1}} \cdot \ln \left(\frac{M_{2}+I_{1}+A_{1}}{M_{1}+I_{1}+A_{1}}\right), \frac{1}{t_{2}-t_{1}} \cdot \ln \left(\frac{M_{1}+I_{2}+A_{1}}{M_{1}+I_{1}+A_{1}}\right), \frac{1}{t_{2}-t_{1}} \cdot \ln \left(\frac{M_{1}+I_{1}+A_{2}}{M_{1}+I_{1}+A_{1}}\right)$, respectively.

The introduction of this approximate expression makes it possible to quantitatively compare the contributions to the WAR change among sectoral water withdrawal changes, population changes, and water availability changes. The evaluation by sector based on Equation (4) was conducted for over $95 \%$ of river basins focused upon in this study, confirming that the approximation error for $\Delta D$ is small enough not to affect the evaluation result.

\subsection{The Water Supply-Demand Model}

The water supply-demand model is a grid-based model with basically $15 \times 15$ minute special resolution. As shown in Figure 1, it is integrated with an agro-land use model to have consistency with evaluations for agricultural land use. The details of the model are described in Hayashi et al. (2013). The outline is as follows: The grid-based annual water availability is estimated from the runoff data projected by atmosphere-ocean coupled general circulation models (AOGCMs) together with global mean temperature change scenario specified, based on a pattern-scaling method. The annual water withdrawal is estimated separately for municipal water, industrial water, and agricultural water. The grid-based municipal water withdrawal is calculated by the product of population and per capita municipal water withdrawal. The per capita municipal water withdrawal is calculated separately for urban and rural areas, taking into account the increases associated with economic growth by country. For the industrial water withdrawal, first, the country total is estimated based on scenarios for the production volumes for water-intensive manufacturing sectors (i.e., iron and steel, the chemical industry, and the pulp and paper sectors) and industrial water-use efficiency. The data on the production volume for each of these sectors and the efficiency are obtained from the Dynamic New Earth 21 plus (DNE21+) model (Akimoto et al., 2010). Then, the industrial water withdrawal is distributed to urban areas in proportion to the urban population in each grid. It is assumed that industrial water is used solely in urban areas. The data on grid-based urban and rural population is developed based on the data for the year 2000 (Netherlands Environmental Assessment Agency [PBL], 2009). It is assumed that the population will concentrate in urban areas and that 
urban areas will spread so as to be in close proximity to each other, according to a study by Grübler et al. (2007). For each of the municipal and industrial water withdrawals, the country total in 2000 agrees with the amount reported by the AQUASTAT database (Food and Agriculture Organization [FAO], 2011a).

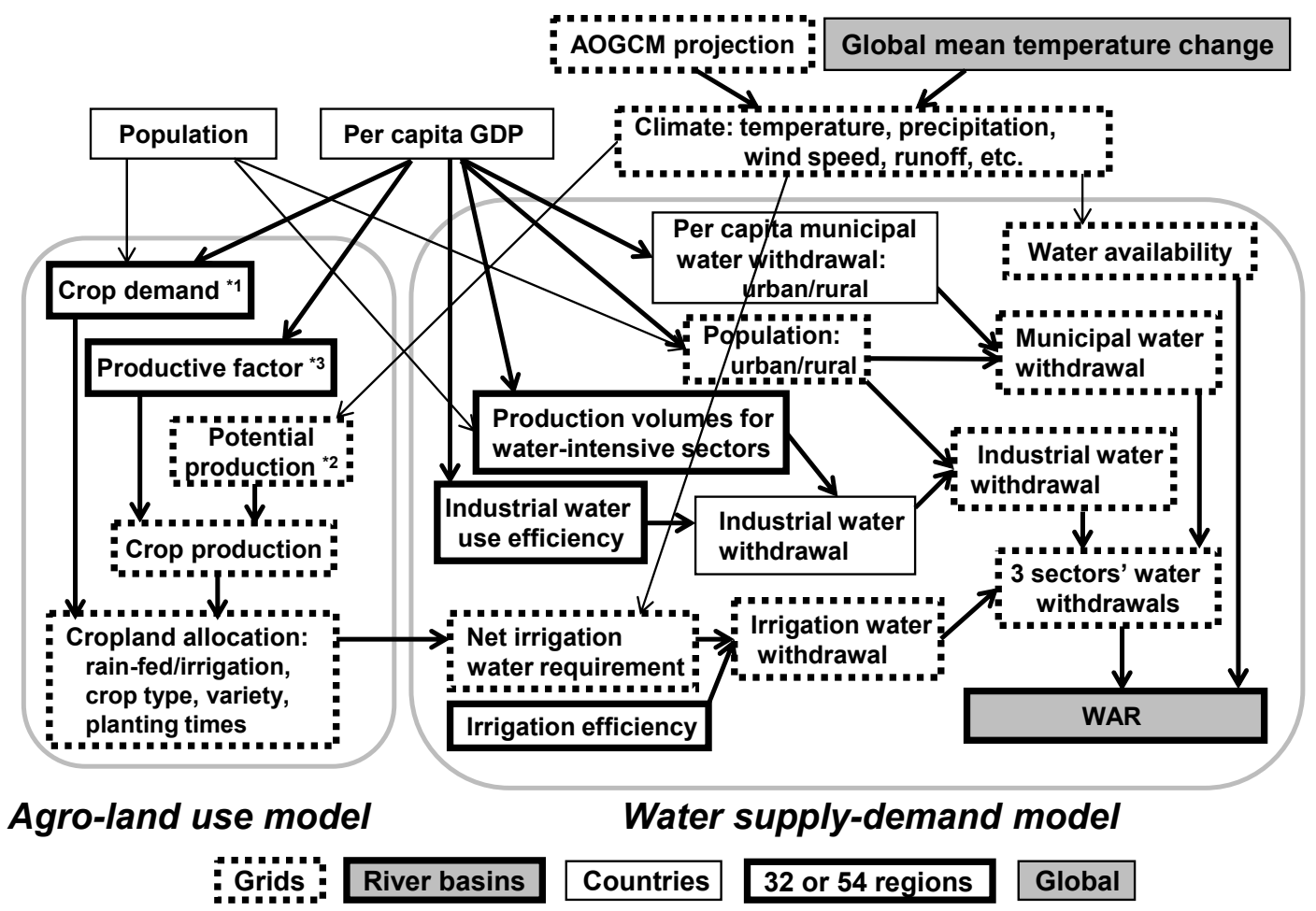

Figure 1. Framework of the water supply-demand model

*1: Crop demand (for wheat, rice, maize, sugar cane, soybeans, oil palm fruit, rapeseed, and others) is estimated to meet the predicted food demand in the future, as well as the biofuel demand (which is assumed to be same as the current level).

*2: The impact of climate change on crop production is estimated based on a framework of the GAEZ model. Adaptations by changing crop variety and planting times are taken into account.

*3: Improvement of productivity caused by technological progress associated with economic growth, land use constraints, etc. (which do not include impacts due to climate change) is assumed based on the historical trend during the period from 1961 to 2007 (FAO, 2011b). For all crops, greater growth is expected in developing regions than in developed regions. For instance, considering rice in scenarios $\mathrm{A}+4$ and $\mathrm{A}+2$ (for the definition of scenarios, refer to section 2.4), the improvement of this factor for Asian regions is assumed in a range from $0.1 \%$ p.a. (for Japan) to $0.8 \%$ p.a. (for Mongolia and the Democratic People's Republic of Korea). (These figures show mean values for the period from 2000 to 2030.)

As agricultural water withdrawal, we focus on irrigation water, which is the dominant form of agricultural water use. The grid-based irrigation water withdrawal is estimated based on the net irrigation water requirements and irrigation efficiency (i.e., the ratio of net irrigation water requirements to irrigation water withdrawals). The numerical values for the irrigation efficiency are derived from a study by Döll and Siebert (2002) (i.e., 0.35 for East and Southeast Asia, and 0.55 for South Asia; to be 0.1 lower for rice). Efficiency is assumed to be constant during this century. The net irrigation water requirement is estimated as the difference between potential evapotranspiration and actual evapotranspiration during the growing period for a crop planted in an irrigation grid. The potential and actual evapotranspiration values are calculated using the Penman-Monteith method and the water-balance method employed in the Global Agro-Ecological Zones (GAEZ) model (Fischer et al., 2002). Information on the irrigation grid, crop type, and planting times are obtained from the results using the agro-land use model. In this model, the grids available for irrigation are based on an irrigation map for the year 2000 (Siebert et al., 2007), and no expansion of the available irrigation grids is allowed in the future according to the 
assumptions of Alcamo et al. (2007). Our estimations for irrigated area and net irrigation water requirements in 2000 agree fairly well with the results obtained by Siebert and Döll (2010).

Data for the river basins are derived from the Total Runoff Integrating Pathways (TRIP) database (Oki, 2001). When we define Asian river basins by the criterion that more than half of a given river basin's area is included in an Asian region (i.e., East Asia, Southeast Asia, or South Asia excluding Iran), the TRIP data covers approximately 800 Asian river basins $\left(20 \times 10^{6} \mathrm{~km}^{2}\right)$. Among them, approximately 700 river basins $\left(18.5 \times 10^{6}\right.$ $\mathrm{km}^{2}$ ) are focused upon; other river basins are excluded mainly due to their very low population densities (i.e., $<1$ person $\mathrm{km}^{-2}$ in 2000).

For grid-based climate projection by AOGCM, data from MIROC 3.2 (Medres) for the SRES-A1B emission scenario were obtained from a Program for Climate Model Diagnosis and Intercomparison (PCMDI) database (2004). Regarding the AOGCM projections, inter-model differences have been suggested (IPCC, 2007); therefore, sensitivity analysis is an ongoing issue.

The calculations are carried out for every decade from 2000 to 2050, and for specific time points for 2070 and 2100 .

\subsection{Scenarios}

We set up three scenarios $(\mathrm{A}+4, \mathrm{~A}+2$, and $\mathrm{B}+4)$, in relation to socioeconomic development and climate change, as shown in Table 1. The time series of socioeconomic development scenarios and climate change scenarios are presented in Tables 2 and 3, respectively. The socioeconomic development scenarios ALPS-A and ALPS-B were developed by Akimoto et al. (2013) giving consideration to historical trends and uncertainties in the future. In scenario ALPS-A, moderate growth of population and per capita GDP is assumed. On the other hand, low population growth and high per capita GDP growth is assumed in scenario ALPS-B.

The global mean temperature changes by 2100 for the climate change scenarios $+4{ }^{\circ} \mathrm{C}$ and $+2{ }^{\circ} \mathrm{C}$ are around + $4{ }^{\circ} \mathrm{C}$ and below $+2{ }^{\circ} \mathrm{C}$, respectively. They were obtained from our previous study, in which the temperature change was estimated based on the greenhouse gases (GHGs) emission scenarios (Akimoto et al., 2012). The scenarios $+4{ }^{\circ} \mathrm{C}$ and $+2{ }^{\circ} \mathrm{C}$ correspond to a baseline GHGs emission scenario and a severe GHGs mitigation scenario, respectively. If the GDP losses due to climate mitigation measures and climate change impacts are taken into account, the GDP value is expected to be lower than that initially assumed without considering these effects. According to our previous study, a change of several percentage points can be expected for the world total in 2100 (Akimoto et al., 2012), and such figures are not large enough to seriously affect the evaluation of water; therefore, we adopted one set of GDP scenario for scenarios A+4 and A+2, regardless the level of global mean temperature change.

Table 1. Scenarios examined

\begin{tabular}{llc}
\hline & \multicolumn{1}{c}{ Socioeconomic development } & Climate change $^{* 1}$ \\
\hline $\mathrm{A}+4:$ & ALPS-A (Moderate growth of population and per capita GDP) & $+4{ }^{\circ} \mathrm{C}$ \\
$\mathrm{A}+2:$ & ALPS-A (Moderate growth of population and per capita GDP) & $+2{ }^{\circ} \mathrm{C}$ \\
$\mathrm{B}+4:$ & ALPS-B (Low population growth and high per capita GDP growth) & $+4{ }^{\circ} \mathrm{C}$ \\
\hline
\end{tabular}

*1: Global mean temperature change in 2100 relative to the pre-industrial level (see Table 3).

Table 2. Time series of socioeconomic development scenarios

\begin{tabular}{lllccccc}
\hline & & & 2000 & 2030 & 2050 & 2070 & 2100 \\
\hline \multirow{2}{*}{ ALPS-A } & Population [billion] $^{* 1}$ & $:$ & 3.3 & 4.3 & 4.6 & 4.5 & 4.3 \\
& Per capita GDP [thousand 2000 US\$] $^{* 2}$ & $:$ & 2.4 & 6.0 & 10 & 14 & 21 \\
& GDP [trillion 2000 US\$] $^{* 1}$ & $:$ & 8 & 26 & 46 & 62 & 91 \\
\hline \multirow{2}{*}{ ALPS-B } & Population [billion] $^{* 1}$ & $:$ & 3.3 & 4.2 & 4.3 & 3.9 & 3.3 \\
& Per capita GDP [thousand 2000 US\$] $^{* 2}$ & $:$ & 2.4 & 6.4 & 12 & 19 & 39 \\
& GDP [trillion 2000 US\$] $^{* 1}$ & $:$ & 8 & 27 & 50 & 75 & 131 \\
\hline
\end{tabular}

*1: Total for the Asian basins.

*2: Mean value for the Asian basins. 
Table 3. Time series of climate change scenarios (global mean temperature change relative to the pre-industrial level) $\left[{ }^{\circ} \mathrm{C}\right]$

\begin{tabular}{lccccc}
\hline & 2000 & 2030 & 2050 & 2070 & 2100 \\
\hline$+4{ }^{\circ} \mathrm{C}:$ & 0.9 & 1.7 & 2.4 & 3.1 & 4.1 \\
$+2{ }^{\circ} \mathrm{C}:$ & 0.9 & 1.6 & 1.8 & 1.9 & 1.9 \\
\hline
\end{tabular}

\section{Results and Discussion}

\subsection{WAR Change Under Scenario A+4}

Figure 2 shows the WAR change rate estimated by river basin for scenario A+4. During the period from 2000 to 2030, an increase in the WAR is estimated for most of the Asian river basins. Large increases of more than $+2 \%$ p.a. are estimated for basins in island countries in Southeast Asia and coastal regions of the continent from China to Pakistan. In contrast, a decrease in the WAR is estimated for basins in Japan and part of the continent. During the period from 2030 to 2050, the increase in the WAR will continue in basins in Southeast Asia, Pakistan, Afghanistan, and northwest China, while the WAR will begin to decrease in large areas in China and India. After 2050, the WAR will gradually stabilize in most of the Asian regions, although the increase or decrease in the WAR will continue in some regions.
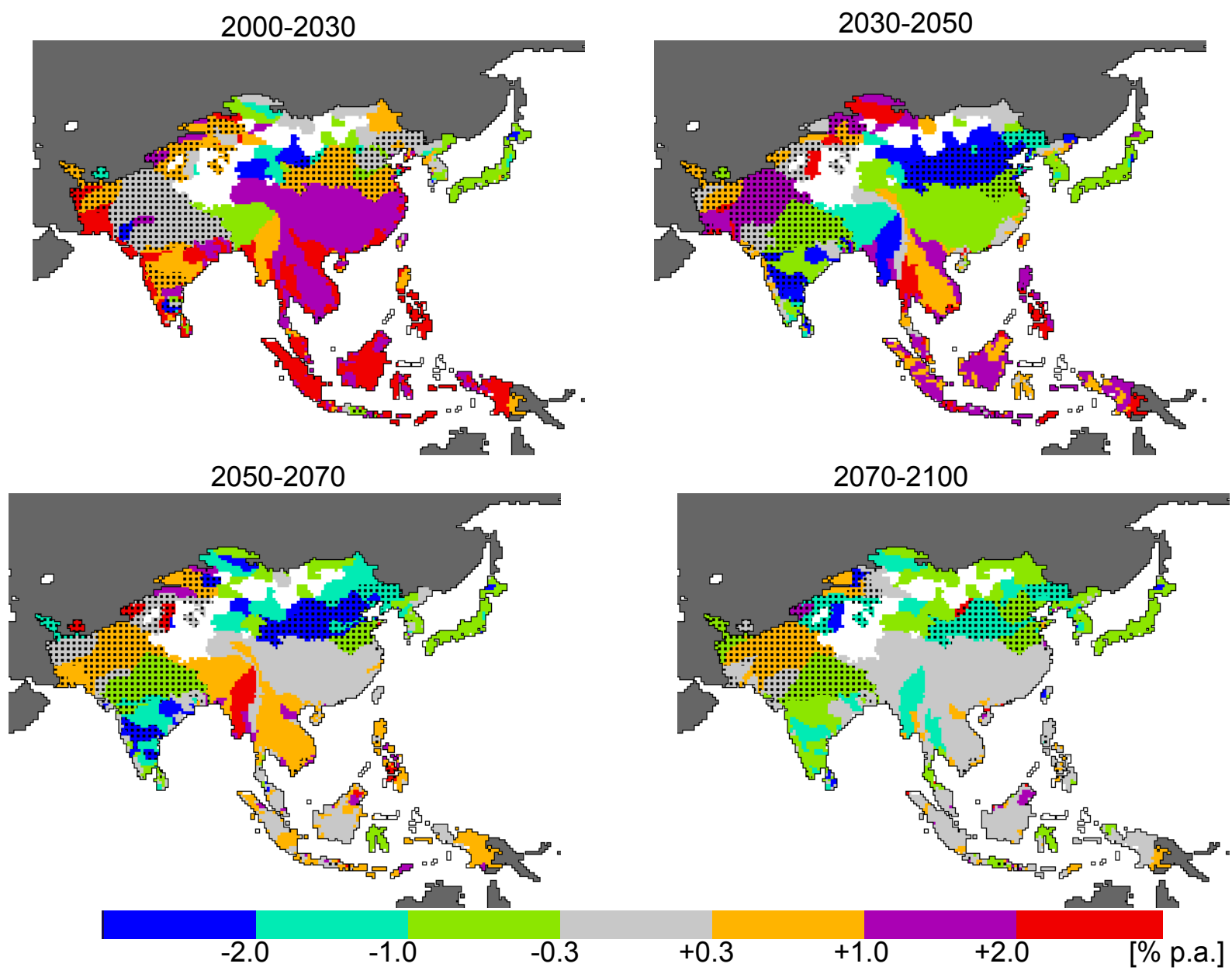

Figure 2. Change rate of the WAR for Asian river basins under scenario $A+4$

Dark gray indicates areas outside Asian river basins. White in Asian river basin areas signifies river basins excluded from this study, mainly due to their very low population densities (see the text in section 2.2). Dotted areas represent river basins estimated as 'river basins having high water stress' based on the criterion $0.4 \leq W A R_{t_{1}}$ for the period from $t_{1}$ to $t_{2}$. 
To clarify the major causes of the changes mentioned above, the change rates of major factors constituting the WAR are evaluated. Figure 3 shows the results for the period from 2000 to 2030. From this figure, it can be noted that the increasing WAR estimated for most of the Asian river basins is mainly caused by population growth and increases in per capita municipal and industrial water withdrawals. For coastal regions of the continent from China to Pakistan, rapid increases in per capita municipal and industrial water withdrawals will significantly contribute to remarkable increases in the WAR. This will be associated with the progress of urbanization in these regions. In the urban areas, the per capita industrial water withdrawal will increase due to enhanced industrial activity, and the per capita municipal water withdrawal will increase due to the improvement of water accessibility and lifestyle changes (e.g., increased frequency of washing and cleaning) associated with economic growth.

The major causes of the decrease in WAR in some regions, such as the north of China and the northeast of India, will be a decrease in per capita agricultural water withdrawal and the increase in water availability. The estimated trend of the decrease in per capita agricultural water withdrawal agrees well with the historical trend since 1960, which was preliminary estimated by us based on the population and the total agricultural water withdrawal in Asia reported by Siklomanov (1999). According to our consideration based on the statistical data (FAO, 2011b) and a report (Alexandratos \& Bruinsma, 2012), the decrease in per capita agricultural water withdrawal since 1960 was caused by the improvement of crop productivity and the decreasing per capita food consumption of rice. (Paddy rice accounts for large amounts of irrigation water withdrawal in Asia.) Both the trend of improvement of crop productivity and that of decreasing per capita food consumption of rice are taken into account in our future scenarios. The change in water availability associated with global warming will differ in different regions. It will increase in some basins in China, India, and Indonesia, leading to decreases in the WAR. However, it will decrease in some basins in Southeast Asia, leading to increases in the WAR.

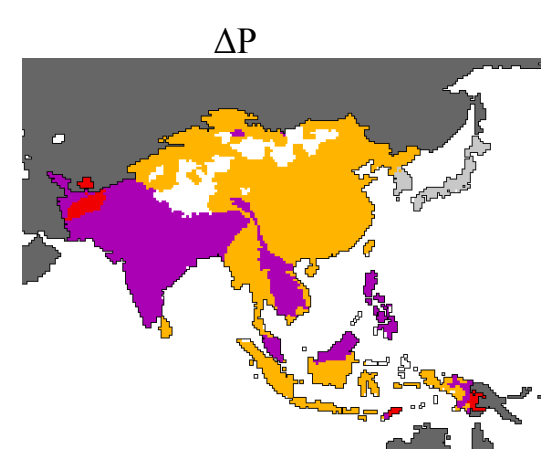

$\Delta{ }^{\prime} \mathrm{M}$
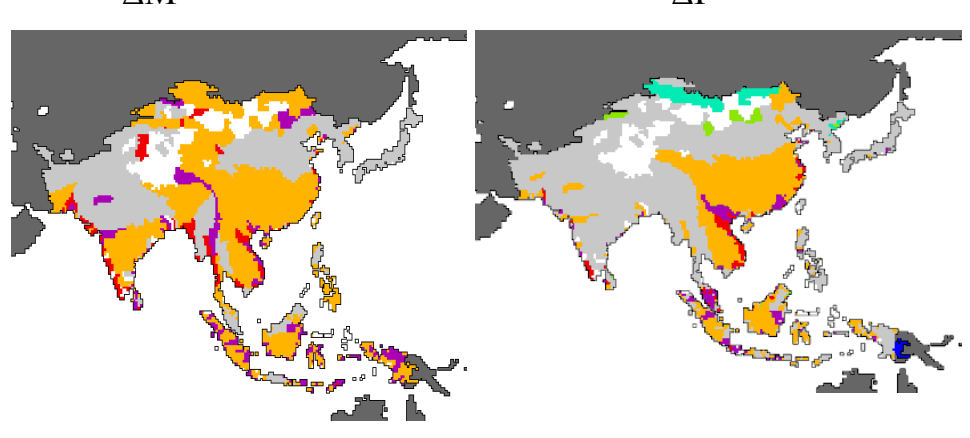

$-\Delta \mathrm{R}$

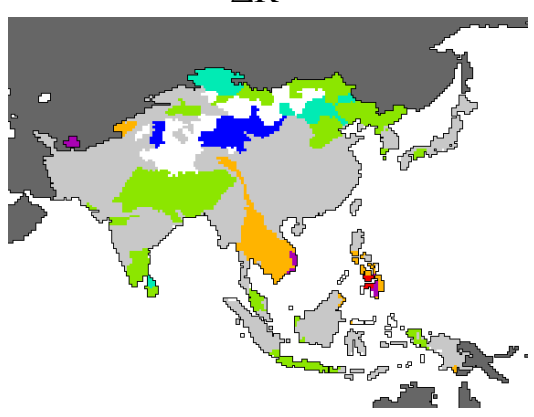

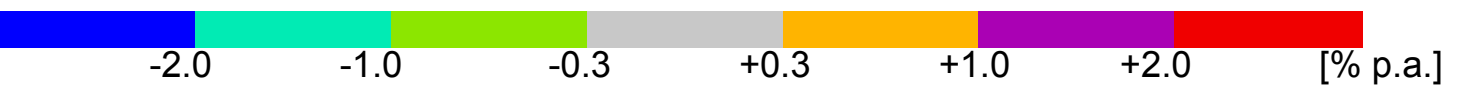

Figure 3. Change rates of the factors constituting the WAR (the period from 2000 to 2030, scenario $\mathrm{A}+4$ )

$\Delta \mathrm{P}$ and $\Delta \mathrm{R}$ represent change rates of population and annual water availability, respectively. $\Delta^{\prime} \mathrm{M}, \Delta^{\prime} \mathrm{I}$, and $\triangle \mathrm{A}$ represent change rates caused by changes in the per capita annual withdrawals of municipal, industrial and agricultural water, respectively (see the definitions in section 2.2). White areas in Asian river basins show the river basins excluded from this study. 


\subsection{Comparisons of WAR Change Among Scenarios}

The WAR change rate estimated by river basin for scenarios $\mathrm{B}+4$ and $\mathrm{A}+2$ is shown in Figure 4 . By comparing scenarios $\mathrm{B}+4$ (Figure 4 (a)) and $\mathrm{A}+4$ (Figure 2), it is noted that the trend of the decreasing WAR will become remarkable after 2030 under scenario $\mathrm{B}+4$. The per capita municipal, industrial, and agricultural water withdrawal changes are not so different between scenarios $\mathrm{B}+4$ and $\mathrm{A}+4$, and the water availability changes for these two scenarios are the same; therefore, the remarkable decrease in the WAR under scenario $\mathrm{B}+4$ is mainly caused by a lower population growth in scenario $\mathrm{B}+4$.

By comparing scenarios $\mathrm{A}+2$ (Figure 4 (b)) and $\mathrm{A}+4$ (Figure 2), it is clear that climate change impacts on the WAR will be suppressed under scenario $A+2$. For instance, the decrease in the WAR estimated in China and India for scenario $\mathrm{A}+2$ is smaller than that for scenario $\mathrm{A}+4$. The reason is that the effect due to the increase in the water availability and the decrease in per capita agricultural water withdrawal expected for these regions under scenario $\mathrm{A}+4$ will be suppressed under scenario $\mathrm{A}+2$; on the other hand, for some regions such as the northwest of Asia (e.g., Afghanistan and Pakistan), the increase in the WAR estimated under scenario A+4 is suppressed under scenario $\mathrm{A}+2$ due to reduction of the decrease in the water availability and increase in the per capita agricultural water withdrawal caused by global warming.

(a) $B+4$

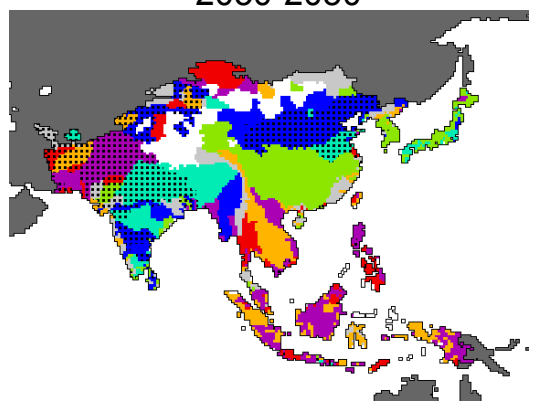

(b) $A+2$

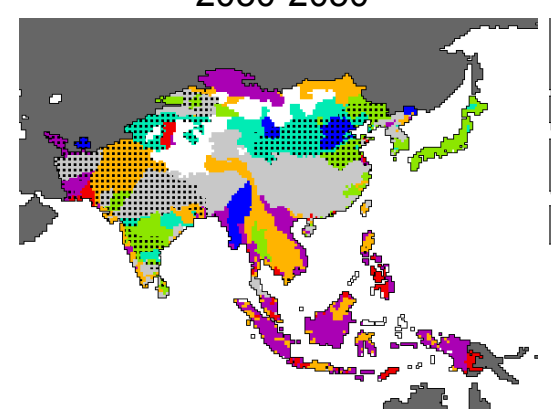

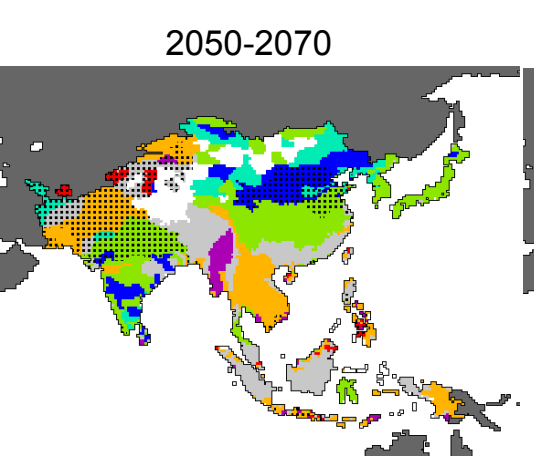
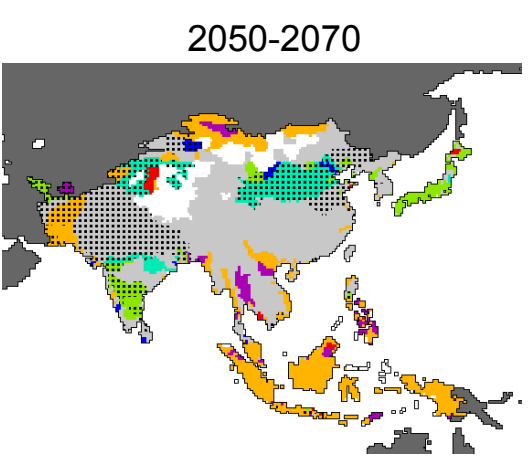

$2070-2100$

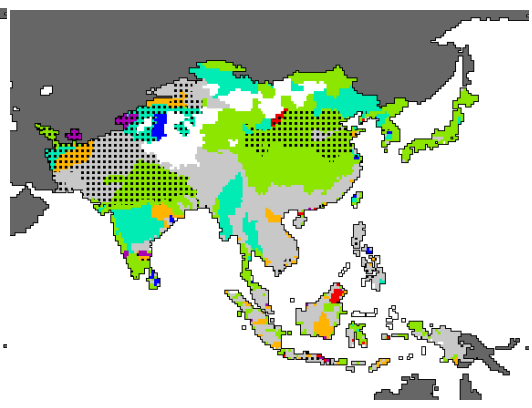

$2070-2100$

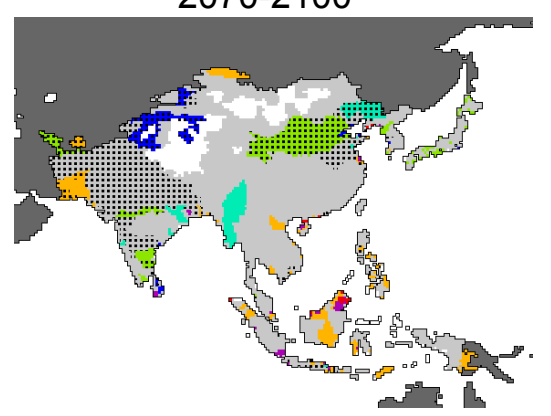

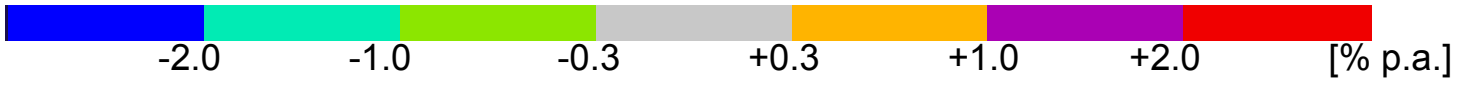

Figure 4. Change rate of the WAR under (a) scenario $\mathrm{B}+4$, and (b) scenario $\mathrm{A}+2$

For dotted areas, white areas, and dark gray areas, refer to the caption of Figure 2.

The figures for the period from 2000 to 2030 are omitted, since they are not so different from that estimated for scenario $\mathrm{A}+4$ (Figure 2).

The percentage figures for areas with increasing and decreasing WAR under each of the scenarios are summarized in Table 4. Under scenario A+4, the figures for areas with increasing WAR, those with decreasing WAR, and those with little change are $61 \%, 13 \%$, and $17 \%$, respectively, for the period of 2000-2030. The remaining $9 \%$ corresponds to areas that are outside the scope of this evaluation, mainly for a reason of the very low population density. During the period of 2030-2050, areas with increasing WAR will be reduced because of 
a slowdown in the growth of population and per capita municipal and industrial water withdrawals; on the other hand, areas with decreasing WAR will be expanded owing to a decrease in per capita agricultural water withdrawal and the enhanced water availability associated with intensified global warming. After 2050, areas with little change will be expanded associated with the stabilization of the WAR.

The figures for scenario $\mathrm{B}+4$ are close to those for scenario $\mathrm{A}+4$, except for the larger values for areas with decreasing WAR after 2050 . This is mainly caused by the remarkable population decrease under scenario $\mathrm{B}+4$ as mentioned above. For scenario $\mathrm{A}+2$, the figures for areas with increasing WAR are almost same as those for scenarios $\mathrm{A}+4$ and $\mathrm{B}+4$, while those for areas with decreasing WAR are smaller than those for scenarios $\mathrm{A}+4$ and $\mathrm{B}+4$. This is mainly caused by that the effect due to the increase in the water availability and the decrease in per capita agricultural water withdrawal expected in regions such as China and India under scenarios $\mathrm{A}+4$ and $\mathrm{B}+4$ will be suppressed under scenario $\mathrm{A}+2$. Consequently, the figures for areas with little change for scenario $\mathrm{A}+2$ are larger than those for scenarios $\mathrm{A}+4$ and $\mathrm{B}+4$.

The trend of areas with increasing WAR outnumbering areas with decreasing WAR during the period from 2000-2030, which is estimated for all three scenarios, is similar to the trend reported by Alcamo et al. (2007), although they evaluated only one period of 1995-2055. Our study evaluates the WAR changes for different periods, and shows that after 2030, changes in the WAR may differ remarkably depending on socioeconomic development and climate change.

Table 4. Percentages of river basin areas with increasing WAR, decreasing WAR, and little change for scenarios $\mathrm{A}+4, \mathrm{~B}+4$, and $\mathrm{A}+2[\%]$

\begin{tabular}{ccccc}
\hline & & $\begin{array}{c}\text { Areas with } \\
\text { increasing WAR }\end{array}$ & $\begin{array}{c}\text { Areas with } \\
\text { decreasing WAR }\end{array}$ & $\begin{array}{c}\text { Areas with little } \\
\text { change }^{* 1}\end{array}$ \\
\hline A+4 & $2000-2030:$ & 61 & 13 & 17 \\
& $2030-2050:$ & 36 & 45 & 10 \\
& $2050-2070:$ & 30 & 34 & 28 \\
& $2070-2100:$ & 11 & 40 & 41 \\
\hline B+4 & $2000-2030:$ & 61 & 16 & 14 \\
& $2030-2050:$ & 36 & 46 & 10 \\
& $2050-2070:$ & 25 & 47 & 20 \\
& $2070-2100:$ & 6 & 51 & 34 \\
\hline A +2 & $2000-2030:$ & 59 & 8 & 24 \\
& $2030-2050:$ & 37 & 27 & 28 \\
& $2050-2070:$ & 24 & 15 & 52 \\
& $2070-2100:$ & 6 & 14 & 71 \\
\hline
\end{tabular}

*1: 'Little change' means the change rate is in the range from $-0.3 \%$ to $+0.3 \%$ p.a.

\subsection{Details of WAR Change and Important Measures for River Basins Threatened by High Water Stress}

The WAR increase in the future is a serious issue, particularly for river basins that are currently threatened by high water stress. In this section, we describe the details of the WAR change, and measures to suppress the WAR increase, taking the 'Huang He' and 'Indus' river basins as examples.

The Huang He river basin has an area of $0.8 \times 10^{6} \mathrm{~km}^{2}$. Our study evaluates conditions there as follows: In 2000, 160 million people lived in this basin, and the annual water availability was $27 \mathrm{~km}^{3} \mathrm{yr}^{-1}\left(230 \mathrm{~m}^{3} \mathrm{person}^{-1} \mathrm{yr}^{-1}\right)$. The WAR was over 3, and the basin was threatened by very high water stress. The annual water withdrawal figures were $5 \%, 15 \%$, and $80 \%$ for municipal, industrial, and agricultural use, respectively. Paddy rice, wheat, and other crops were produced in the irrigated area.

Figure 5 shows estimations of the WAR and change rates of its factors in the future for this river basin. The WAR (Figure 5 (a)) is expected to increase by around 2030, and to decrease drastically thereafter. The expected major causes for the increase by around 2030 are population growth and increases in the per capita industrial and 
municipal water withdrawals, as shown in Figures 5 (b), (d), and (d). The major causes of the decrease after 2030 are expected to be an increase in water availability associated with climate change, and a decrease in per capita agricultural water withdrawal. The decrease in the per capita agricultural water withdrawal is expected as a result of climate change impacts, and the improvement of the crop productivity associated with the economic growth. The WAR decrease weakens in scenario $\mathrm{A}+2$ compared to those in scenarios $\mathrm{A}+4$ and $\mathrm{B}+4$, since the effect due to climate change on the increase in water availability and the decrease in per capita agricultural water withdrawal will be suppressed in scenario $\mathrm{A}+2$.

These results suggest that measures will be necessary in this river basin by around 2030. In particular, measures to handle the population increase and improvement of efficiency for industrial and municipal water use will be important.

(a) WAR

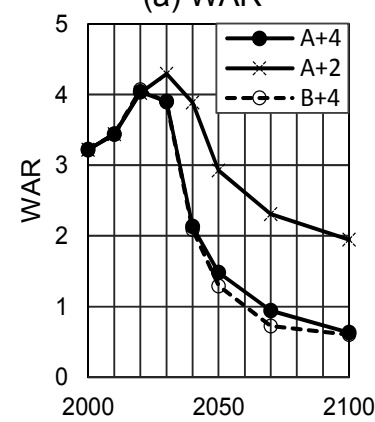

(b) $A+4$

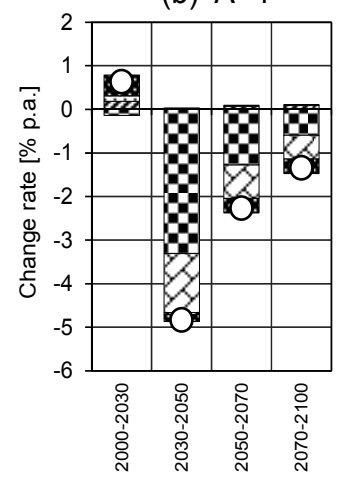

(c) $A+2$

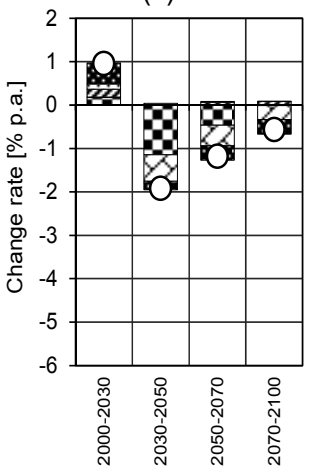

(d) $\mathrm{B}+4$

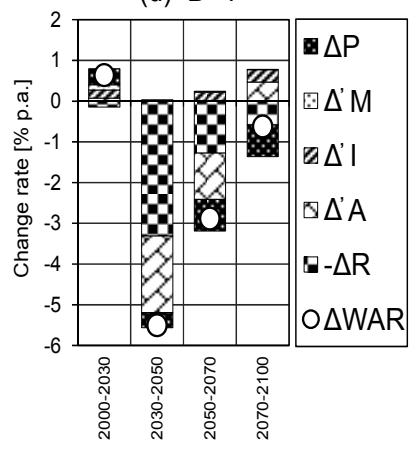

Figure 5. Time series for the Huang He river basin

(a) The WAR, and change rates for (b) scenario $\mathrm{A}+4$, (c) scenario $\mathrm{A}+2$, and (d) scenario $\mathrm{B}+4$

(a) WAR

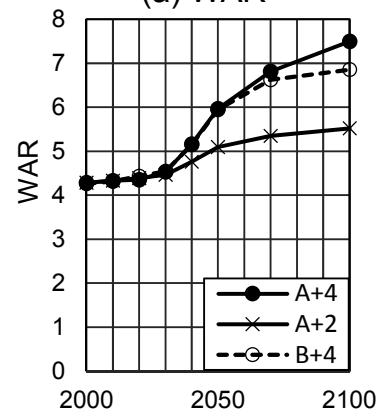

(b) $\mathrm{A}+4$

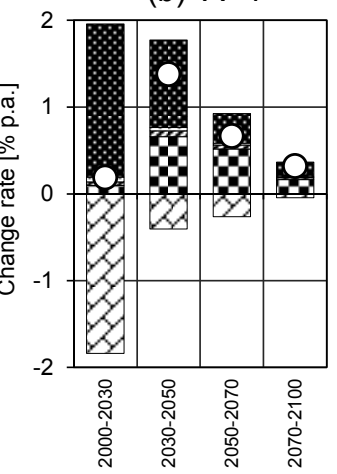

(c) $\mathrm{A}+2$

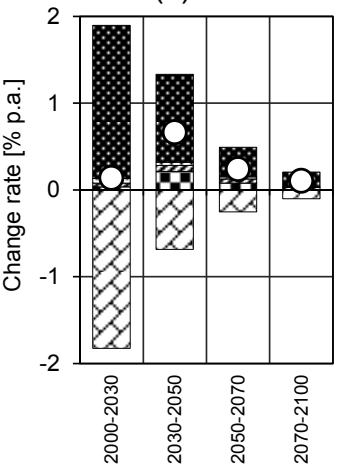

(d) $\mathrm{B}+4$

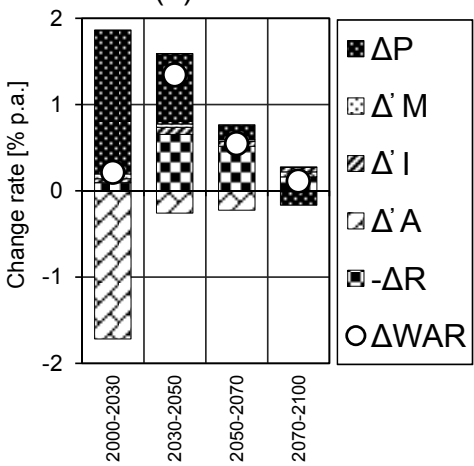

Figure 6. Time series for Indus river basin

The Indus river basin has an area of $1.0 \times 10^{6} \mathrm{~km}^{2}$. According our estimates, in 2000, 190 million people lived in this basin, and the annual water availability was $70 \mathrm{~km}^{3} \mathrm{yr}^{-1}\left(370 \mathrm{~m}^{3}\right.$ person $\left.{ }^{-1} \mathrm{yr}^{-1}\right)$. The WAR was over 4 , and the basin was threatened very high water stress. More than $95 \%$ of the annual water withdrawal was used for agriculture. Paddy rice, wheat, and other crops were produced in the irrigated area.

Figure 6 shows estimations for the WAR and change rates of its factors in the future for this river basin. The WAR is expected to be almost constant by around 2030, and to increase after that. For the period from 2000 to 2030, the population is expected to increase, and to contribute to the WAR increase. Meanwhile, the per capita agricultural water withdrawal is expected to decrease, and to contribute to the WAR decrease. Consequently, the WAR is expected to almost constant. The decrease in the per capita agricultural water withdrawal is mainly a result of improvement in crop productivity. The crop productivity in this region was very low (for instance, the 
for paddy rice in 2000 yield was 3.0, 3.9, and 6.3 ton $\mathrm{ha}^{-1}$ for Pakistan, the global mean, and China, respectively (FAO, 2011)); therefore, it is expected to steadily improve with economic growth.

After 2030, the decrease in the per capita agricultural water withdrawal dwindles, stemming from climate change impacts. The population growth also slows down; however, it is large enough to increase the WAR. In addition to these factors, the water availability decreases as a result of climate change, and becomes one of significant causes of the WAR increase.

These results suggest that coping with the decrease in the water availability, which is projected to become apparent after around 2030, will be important in this river basin. In addition, measures to handle the population increase may be necessary to suppress an increase of the WAR.

\section{Conclusions}

Ensuring a stable fresh water supply is a critical issue for Asia. To make progress with water management, understanding future changes in the ratio of the water demand and availability, as well as the major causes of such changes, are important. This study evaluates changes in the ratio by river basin in Asian regions based on the annual water withdrawal-to-availability ratio (WAR) under the three different future long-term scenarios for socioeconomic development and climate change. Furthermore, to clarify the major causes of the change, the contributions of major factors are evaluated. The findings of this study are as follows:

- The WAR will increase in 59\%-61\% of the Asian river basin areas by around 2030, as a result of population growth and the increase in per capita municipal and industrial water withdrawals. In some costal basins in which progress with urbanization is expected, increases in the per capita municipal and industrial water withdrawals may be more significant than population growth. On the other hand, the WAR will decrease in $8 \%-16 \%$ of the Asian river basin areas due to the increase in water availability associated with global warming and the decrease in per capita water agricultural withdrawal.

- After 2030, there will be a reduction of areas with increasing WAR because of a slowdown in the growth of both population and per capita municipal and industrial water withdrawals, while there will be an expansion of areas with decreasing WAR, mainly caused by continual decrease in per capita agricultural water withdrawal and intensified water availability. Differences in WAR changes among the three scenarios will become gradually clear. Under the low population growth scenario, the population decrease is expected to reduce the WAR in many Asian basins. Under the mitigated climate change scenario, changes in water availability and per capita agricultural water withdrawal are expected to be suppressed. Consequently, increases in the WAR estimated under the baseline climate change scenario will be suppressed in regions such as the northwest of Asia (e.g., Afghanistan and Pakistan); on the other hand, decreases in the WAR estimated under the baseline climate change scenario will be suppressed in regions such as China and India.

- Significant measures to suppress the WAR increase will be different in different river basins, depending on the causes for the WAR increase. For instance, measures to deal with the population increase and efforts to improve industrial and municipal water use by around 2030 will be important in the Huang He river basin. In the Indus river basin, the coping with a decrease in water availability after around 2030 will be important. In addition, measures to handle population increase will be necessary.

Our study clearly shows that the direction, the degree, the causes, and the period of the WAR change will differ among river basins, depending on the socioeconomic development and climate change. This implies that water resource management should be discussed by river basin, taking into account of uncertainties in major causes. This paper evaluates three highly consistent scenarios for socioeconomic development and climate change. However, uncertainties remain, particularly regarding regional climate change. We used the grid-based climate projection by an AOGCM (i.e., MIROC 3.2 (Medres)), and sensitivity analysis based on the projections by other AOGCMs remains to be addressed. In addition, the impacts of extreme weather events such as floods and droughts present uncertainties. Further research will be required.

\section{Acknowledgements}

The authors greatly appreciate the assistance of Professor Yoichi Kaya, President of RITE, and Professor Kenji Yamaji, Director General of RITE. We also acknowledge the assistance provided by the modeling groups in making their simulations available for analysis, the Program for Climate Model Diagnosis and Intercomparison (PCMDI) for collecting and archiving the CMIP3 model output, and the World Climate Research Programme's (WCRP's) Working Group on Coupled Modelling (WGCM) for organizing the model data analysis activity. The WCRP Coupled Model Intercomparison Project (CMIP3) multi-model dataset is supported by the Office of Science, U.S. Department of Energy. 


\section{References}

Akimoto, K., Sano, F., Hayashi, A., Homma, T., Oda, J., Wada, K., \& Tomoda, T. (2012). Consistent assessments of pathways toward sustainable development and climate stabilization. Natural Resources Forum, 36(4), 231-244. http://doi/10.1111/j.1477-8947.2012.01460.x/abstract

Akimoto, K., Sano, F., Homma, T., Oda, J., Nagashima, M., \& Kii, M. (2010). Estimates of GHG emission reduction potential by country, sector, and cost, Energy Policy, 38(7), 3384-3393. http://dx.doi.org/10.1016/j.enpol.2010.02.012

Akimoto, K., Sano, F., Homma, T., Tokushige, K., Nagashima, M., \& Tomoda, T. (2014). Assessment of the emission reduction target of halving $\mathrm{CO}_{2}$ emissions by 2050: Macro-factors analysis and model analysis under newly developed socio-economic scenarios. Energy Strategy Reviews, 2(3-4), 246-256.

Alcamo, J., Flörke, M., \& Märker, M, (2007). Future long-term changes in global water resources driven by sosio-economic and climate changes. Hydrological Science, 52(2), 247-275. http://dx.doi.org/10.1623/hysj.52.2.247

Alexandratos, N., \& Bruinsma, J. (2012). World agriculture towards 2030/2050: the 2012 revision. ESA Working paper No. 12-03. Rome, FAO. Retrieved from http://www.fao.org/fileadmin/templates/esa/Global_persepctives/world_ag_2030_50_2012_rev.pdf

Arnel, N. W. (2004). Climate change and global water resources: SRES emissions and socio-economic scenarios. Global Environmental Change, 14, 31-52. http://dx.doi.org/10.1016/j.gloenvcha.2003.10.006

Döll, P., \& Siebert, S. (2002). Global modeling of irrigation water requirements. Water Resources Research, 38(4), 8-1. http://dx.doi.org/10.1029/2001WR000355

Fischer, G., van Velthuizen, H., Shah, M., \& Nachtergaele, F. (2002). Global agro-ecological assessment for agriculture in the 21st century. Retrieved from http://www.iiasa.ac.at/Research/LUC/SAEZ/index.html

Food and Agriculture Organization. (2011a). AQUASTAT main country database. Retrieved from http://www.fao.org/nr/water/aquastat/data/query/index.html?lang=en. Cited 10 Nov 2011

Food and Agriculture Organization. (2011b). FAOSTAT database. Retrieved from http://faostat.fao.org/site/291/default.aspx. Cited 11 Oct 2011

Fung, F., Lopez, A., \& New, M. (2011). Water availability in $+2 \mathrm{C}$ and $+4 \mathrm{C}$ worlds. Philosophical transactions of the Royal Society A: mathematical, physical and engineering sciences, 369(1934), 99-116. http://dx.doi.org/10.1098/rsta.2010.0293

Gerten, D., Lucht, W., Ostberg, S., Heinke, J., Kowarsch, M., Kreft, H., \& Schellnhuber, H. J. (2013). Asynchronous exposure to global warming: freshwater resources and terrestrial ecosystems. Environmental Research Letters, 8(3), 034032.

Gosling, S. N., \& Arnell, N. W. (2013). A global assessment of the impact of climate change on water scarcity. Climatic Change, 1-15.

Grübler, A., O’Neill, B., Riahi, K., Chirkov, V., Goujon, A., Kolp, P., \& Slentoe, E. (2007). Regional, national, and spatially explicit scenarios of demographic and economic change based on SRES. Technological Forecasting \& Social Change, 74, 980-1029. http://dx.doi.org/10.1016/j.techfore.2006.05.023

Hanasaki, N., Fujimori, S., Yamamoto. T., Yoshikawa, S., Masaki, Y., Hijioka, Y., \& Kanae, S. (2013). A global water scarcity assessment under shared socio-economic pathways - Part2: Water availability and scarcity. Hydrology and Earth System Sciences, 17, 2393-2413. http://dx.doi.org/10.5194/hess-17-2393-2013

Hanasaki, N., Kanae, S., Oki, T., Masuda, K., Motoya, K., Shirakawa, N., \& Tanaka, K. (2008). An integrated model for the assessment of global water resources -Part 2: Applications and assessments. Hydrology and $\begin{array}{llll}\text { Earth System } & \text { Sciences, } & 1027-1037 .\end{array}$ http:/www.hydrol-earth-syst-sci.net/12/1027/2008/hess-12-1027-2008.pdf

Hayashi, A., Akimoto, K., Tomoda, T., \& Kii, M. (2013). Global evaluation of the effects of agriculture and water management adaptations on the water-stressed population, Mitigation and Adaptation of Strategies for Global Change, 18 (5), 591-618. http://dx.doi.org/10.1007/s11027-012-9377-3

Intergovernmental Panel on Climate Change. (2000). Special report on emissions scenarios. Cambridge: Cambridge University Press.

Intergovernmental Panel on Climate Change. (2007). Climate change 2007: the physical science basis. 
Cambridge: Cambridge University Press.

Netherlands Environmental Assessment Agency [PBL]. (2009). History database of the global environment. Retrieved from http://themasites.pbl.nl/en/themasites/hyde/index.html

Oki, T. (2001). Total runoff integrating pathways (TRIP). Retrieved from http://hydro.iis.u-tokyo.ac.jp/\%7Etaikan/TRIPDATA/TRIPDATA.html

Oki, T., \& Kanae, S. (2006). Global Hydrological Cycles and World Water Resources. Science, 313(5790), 1068-1072. http://dx.doi.org/10.1126/science.1128845

Program for Climate Model Diagnosis and Intercomparison. (2004). WCRP CMIP3 multi-model database. Retrieved from http://www-pcmdi.llnl.gov/ipcc/about_ipcc.php. Cited 7 May 2010

Raskin, P., Gleick, P., Kirshen, P., Pontius, G., \& Strzepek, K. (1997). Comprehensive assessment of the freshwater resources of the world. Stockholm Environment Institute, Stockholm, Sweden.

Shiklomanov, I. A. (1999). World water resources and their use a joint shi/unesco product. Retrieved from http://webworld.unesco.org/water/ihp/db/shiklomanov/

Siebert, S., \& Döll, P. (2010). Quantifying blue and green virtual water contents in global crop production as well as potential production losses without irrigation. Journal of Hydrology, 384(3-4), 198-217.

Siebert, S., Döll, P., Feick, S., Hoogeveen, J., \& Frenken, K. (2007). Global Map of Irrigation Areas version 4.0.1. Johann Wolfgang Goethe University, Frankfurt am Main, Germany / Food and Agriculture Organization of the United Nations, Rome, Italy. Retrieved from https://www2.uni-frankfurt.de/45218039/Global_Irrigation_Map

United Nations. (2007). World population prospects: the 2006 revision. Retrieved from http://www.un.org/esa/population/publications/wpp2006/wpp2006.htm

United Nations. (2011). World population prospects: the 2010 revision. Retrieved from http://esa.un.org/wpp/Documentation/WPP\%202010\%20publications.htm

Vörösmarty, C. J., Green, P., Salisbury, J., \& Lammers, R. B. (2000). Global water resources: vulnerability from $\begin{array}{lllll}\text { climate change and population } & \text { growth. }\end{array}$ http://dx.doi.org/10.1126/science.289.5477.284

\section{Copyrights}

Copyright for this article is retained by the author(s), with first publication rights granted to the journal.

This is an open-access article distributed under the terms and conditions of the Creative Commons Attribution license (http://creativecommons.org/licenses/by/3.0/). 